\title{
Hội đồng Nghiên cứu Úc 'quay xe' sau chính sách preprints bất hợp lý
}

sciencevietnam

SSHPA (21-09-2021) - Sau khi công bố chính sách bất hợp lý với preprints vào cuối tháng 8 vừa qua, Hội đồng Nghiên cứu Úc đã phải rút lại quy định sau sự phản đối kịch liệt từ cộng đồng khoa học [1].

Trong thông báo được đưa ra ngày 14-9-2021 trên trang chủ, Australian Research Council (ARC) sẽ không loại các hồ sơ có đề cập hoặc trích dẫn tới preprint trong danh mục các công trình nghiên cứu hoặc đơn đề xuất nghiên cứu [2]. Tuy nhiên, sự thay đổi này sẽ chỉ áp dụng trong tương lai, và các trường hợp đã bị loại trước đó sẽ không được xem xét lại.

\section{Australian Government}

Australian Research Council

Home

\section{Adjustments to the ARC's position on preprints}

Home " News and Publications " Media " Communiques " Adjustments to the ARC's position on preprints

14 September 2021

Theo Nature, các nhà khoa học bị từ chối do chính sách preprints này vẫn có thể nộp đơn xem xét lại quyết định. Tuy vậy, hầu hết các nhà khoa học đều cho rằng quá trình kháng án này chỉ gây thêm rắc rối cho các nhà nghiên cứu, đồng thời cũng nhận định quyết định của $\mathrm{ARC}$ dù tốt nhưng vẫn còn nửa vời [1].

Quyết định 'quay xe’ của Hội đồng Nghiên cứu Úc rất thiết thực trong bối cảnh cởi mở hiện nay. Tuy nhiên, việc không xem xét lại các quyết định đã đưa ra có thể để lại ân tượng xấu đối với cộng đồng khoa học Ûc. Các chính sách khoa học được đưa ra là để tạo điều kiện tốt nhất cho các nhà khoa học $[3,4]$.

\section{Tài liệu tham khảo:}

[1] Watson C. (2021). Australian funder backflips on controversial preprint ban. Nature, doi: https://doi.org/10.1038/d41586-021-02533-3

[2] ARC. (2021). Adjustments to the ARC's position on preprints. Australian Research Council. URL: https://www.arc.gov.au/news-publications/media /communiques/adjustments-arcs-position-preprints 
[3] Vuong QH. (2019). Breaking barriers in publishing demands a proactive attitude. Nature Human Behaviour, 3(10), 1034.

[4] Vuong QH. (2018). The (ir)rational consideration of the cost of science in transition economies. Nature Human Behaviour, 2(1), 5.

Last modified: 9/21/2021 5:10 PM Views: 110

\section{Bài liên quan:}

- Truyền thông khoa học trong thời kỳ COVID-19.

- Hội đồng Nghiên cứu Úc bị chỉ trích dữ dọi vì chính sách bất hợp lý với preprints

- Lấy trứng chọi đá: Liệu tạp chí khoa học có bị thay thế bởi preprint?

- COVID-19 và thế giới xuất bản học thuât

- Lịch sử hình thành các kho lưu trữ dữ liệu 